\title{
Immunogold study on lectin binding in the porcine zona pellucida and granulosa cells
}

\author{
F. Parillo, ${ }^{*}$ C. Dall'Aglio, ${ }^{*}$ A. Verini Supplizi, ${ }^{\circ}$ P. Ceccarelli, ${ }^{*}$ A.M. Gargiulo* \\ *Department of Biopathological Veterinary Science, ${ }^{\circ}$ Department of Technologies and Biotechnologies \\ of the Animal Productions, Faculty of Veterinary Medicine, Università degli Studi di Perugia, Italy
}

\begin{abstract}
.
(C)2003, European Journal of Histochemistry

An ultrastructural localization of lectin receptors on the zona pellucida (ZP) of porcine antral oocytes and on the granulosa cells was performed using a panel of horseradish peroxidase-labelled lectins in conjunction with antiperoxidase antibody and protein A-gold. In some cases, lectin incubation was preceded by sialidase digestion. WGA-, Con-A-, UEA-I-, RCA-I-, PNA- and SBA-reactive sites were distributed differently in the porcine ZP. Sialidase digestion increased the positivity obtained with RCA-I and it was necessary to promote PNA and SBA reactivity. These results indicated that the ZP contained $\mathrm{N}$-acetylglucosamine, $\alpha$-mannose, $\alpha$ fucose, $\beta$-Gal-(1-4)GIcNAc, $\beta$-Gal- (1-3)GaINAc, $\beta$-GalNAc and sialic acid residues. We also observed the presence of vesicles in both the ooplasm and granulosa cells, showing a similar lectin binding pattern to that of the ZP, thus suggesting that the oocyte and granulosa cells are the site of synthesis of ZP glucidic determinants.
\end{abstract}

Correspondence: F. Parillo, Department of Biopathological Veterinary Science, Faculty of Veterinary Medicine, Università degli Studi di Perugia, via San Costanzo 4, 06126 Perugia, Italy. Phone: international +39.075.5857631. Fax: international +39.075.5857631. E-mail: anatvet@unipg.it

Key words: Zona pellucida, granulosa cells, lectin.

Paper accepted on April 16, 2003

European Journal of Histochemistry

2003; vol. 47 issue 4 [0ct-Dec]: 353-358
T he Zona Pellucida (ZP), a unique extracellular coat that surrounds the mammalian oocytes and preimplantation embryo, plays essential functions during the fertilisation and early stages of zygote development (Wassarmann, 1994; Sinowatz et al., 2001). The ZP of most mammals is composed of three major, highly glycosylated glycoproteins, which, in the mouse, are called ZPA, ZPB and ZPC (Bleil and Wassarmann, 1990). Zona carbohydrates strongly influence the physicochemical properties of ZP glycoproteins and participate in sperm-zona recognition events, probably as ligands for complementary carbohydrate-binding proteins on the sperm surface.

Comparative histochemical studies have shown species-dependent variations in the expression and distribution of carbohydrates throughout the ZP (Parillo et al., 1996, 1998, 1999, 2000, 2001a,b; Verini Supplizi et al., 1996; Chapman et al., 2000). The organisation of the ZP in morphological distinct bands, which have been demonstrated by light microscopic studies in the above mentioned investigations, was also found in the rat, mouse and hamster at the ultrastructural level (Roux and Kan, 1991; Avilés et al., 1996, 2000; El Mestrah and Kan, 2001).

The site of ZP glycoprotein production may vary among species. In the majority of mammals, both the oocyte and granulosa cells are involved in the origin of the ZP (Sinowatz et al., 2001). Conversely, the oocyte is the only source of the ZP in mice (Bleil and Wassarmann, 1980; Flèchon et al., 1984; Epifano et al., 1995) and rats (Avilés et al., 1994). The involvement of both the oocyte and follicular cells in the secretion of the porcine ZP was demonstrated in an immunocytochemical study carried out using antibodies directed against porcine ZP $3 a$ and ZP3b glycoproteins (Sinowatz et al., 1995). Finally, in this regard, it has been demonstrated that in the hamster, besides oocyte and/or granulosa cells, involved in ZP production, the oviductal cells con- 
tribute to the synthesis of certain ZP glycocoproteins after oocyte ovulation (Kan et al., 1989; Roux and Kan, 1991; El-Mestrah and Kan, 2001).

In the present cytochemical study, we used horseradish-peroxidase-conjugated lectins to analyse the ultrastructural distribution of the glycoprotein glucidic residues present in the porcine $Z P$, in the ooplasm and in the granulosa cells.

\section{Materials and Methods}

\section{Oocytes-granulosa cell collection}

Porcine oocyte-granulosa cell complexes were aspirated from antral follicles (3-4 mm diameter) present in the ovaries of adult sows immediately after slaughter.

\section{Cytochemical labelling}

The oocyte-granulosa cell complexes were fixed in $2.5 \%$ gluteraldehyde in $0.1 \mathrm{M}$ cacodylate buffer $\mathrm{pH}$ 7.4 for $2 \mathrm{hr}$ at room temperature. Subsequently, the oocyte-granulosa cell complexes were processed for electron microscopy according to the procedures previously described by Menghi et al. $(1996 a, b)$ and Scala et al. (1992) which were partially modified. The cumulus masses were dehydrated in a series of $50 \%, 70 \%$ and $90 \%$ acetone and embedded in Bioacryl resin (Bio-optica, Milan, Italy). Thereafter, ultrathin sections (about $80 \mathrm{~nm}$ thick), which were placed on parlodion-coated 200 mesh nickel grids, were obtained from these samples. The nickel grids were preincubated at room temp. for $10 \mathrm{~min}$ in $0.5 \mathrm{M}$ TBS (Tris Buffered Saline) pH 7.4 containing $0.25 \%$ BSA (Bovine Serum Albumine) and then, incubated at room temp. for $3 \mathrm{~h}$ with horseradishperoxidase (HRP) conjugated lectins diluted in TBS, pH 7.4 plus $1 \%$ BSA. The lectins used, their carbohydrate specificity and the optimal concentrations are shown in Table 1. After lectin incubation, sections were rinsed with $0.05 \mathrm{M}$ TBS containing $1 \%$ BSA and reacted with anti-HRP antibody (raised in rabbit and diluted 1:100 in TBS-1\% BSA) at room temp. for 1 h. Then, sections were washed with $0.05 \mathrm{M}$ TBS-1\% BSA and treated with protein A gold (10 or $20 \mathrm{~nm}$ ) diluted 1:50 in 0.1M TBS, pH 7.4 plus $1 \%$ BSA and $0.05 \%$ Tween 20 , at room temp. for $1 \mathrm{~h}$. Finally, after counterstaining with uranyl acetate and lead citrate, sections were examined with a Philips EM 208 electron microscopy at $80 \mathrm{KV}$.
Table 1. Lectins used and their carbohydrate specificities

\begin{tabular}{|c|c|c|c|}
\hline Source of lectin & Acronym & Lectin specificity* & $\begin{array}{l}\text { Lectin concentration } \\
(\mu \mathrm{g} / \mathrm{mL})\end{array}$ \\
\hline Arachis hypogaea & PNA & $\beta$-D-Gal-(1 $\rightarrow 3)$-D-GalNAc & 40 \\
\hline Ulex europaeus & UEA-I & $\alpha$-L-Fuc & 20 \\
\hline Lotus tetragonolobus & LTA & $\alpha$-L-Fuc & 20 \\
\hline Dolichos biflorus & DBA & $\alpha$-D-GalNAc & 10 \\
\hline Glycine max & SBA & $\alpha-D-G a I N A c>\beta-D-G a I N A c$ & 10 \\
\hline Triticum vulgare & WGA & GlcNAc>sialic acid & 10 \\
\hline Canavalia ensiformis & Con-A & $\alpha-D-M a n>\alpha-D-G \mid c$ & 20 \\
\hline Ricinus communis & RCA-I & $\beta$-D-Gal-(1 $\rightarrow 4)$-D-GlcNAC & 50 \\
\hline
\end{tabular}

* $\beta$-D-Gal $=\beta$-D-galactose; $\alpha$-D-Gal $=\alpha$-D-galactose; $D$-GalNAC = D-N-acetylgalactosamine; $\beta-D$-GalNAc = $\beta-D-N$-acetylgalactosamine; $\alpha$-D-GalNAc $=\alpha-D-N$-acetylgalactosamine; GIcNAC = N-acetylglucosamine; $\alpha$-L-Fuc $=\alpha$-L-fucose; $\alpha$-D-Man $=\alpha$-D-mannose; $\alpha$-D-Glc $=\alpha$-D-glucose.

All the HRP-labelled lectins, the anti-HRP antibody and protein A gold were purchased from Sigma Chemical Co (St. Louis, MO, USA).

\section{Enzymatic treatment}

Before WGA, PNA, SBA, RCA-I and DBA lectin incubation, tissue sections were digested with sialidase (neuraminidase type $\mathrm{V}$, from Clostridium perfringens) at a concentration of $0.86 \mathrm{U} / \mathrm{mL}$ in acetate buffer $\mathrm{pH} 5.5$ containing $10 \mathrm{mM} \mathrm{CaCl}_{2}$ for 16h at $37^{\circ} \mathrm{C}$ (Menghi et al., 1996b).

\section{Controls}

The control for the specificity of lectin cytochemistry was carried out either by adding the specific competing sugar at a concentration of 0.2-0.4 $\mathrm{M}$ in the lectin solutions or by omitting the anti-peroxidase antibody or lectin HRP conjugates. Controls for enzymatic digestion were performed by substituting the enzyme with its corresponding buffer.

\section{Results}

\section{Zona pellucida}

The ZP of oocytes exhibited heavy to moderate labelling over its entire thickness when labelled with WGA and Con-A (Figures 1a-2a). Sialidase digestion did not modify WGA positivity.

UEA-I lectin showed a slight reactivity preferen- 

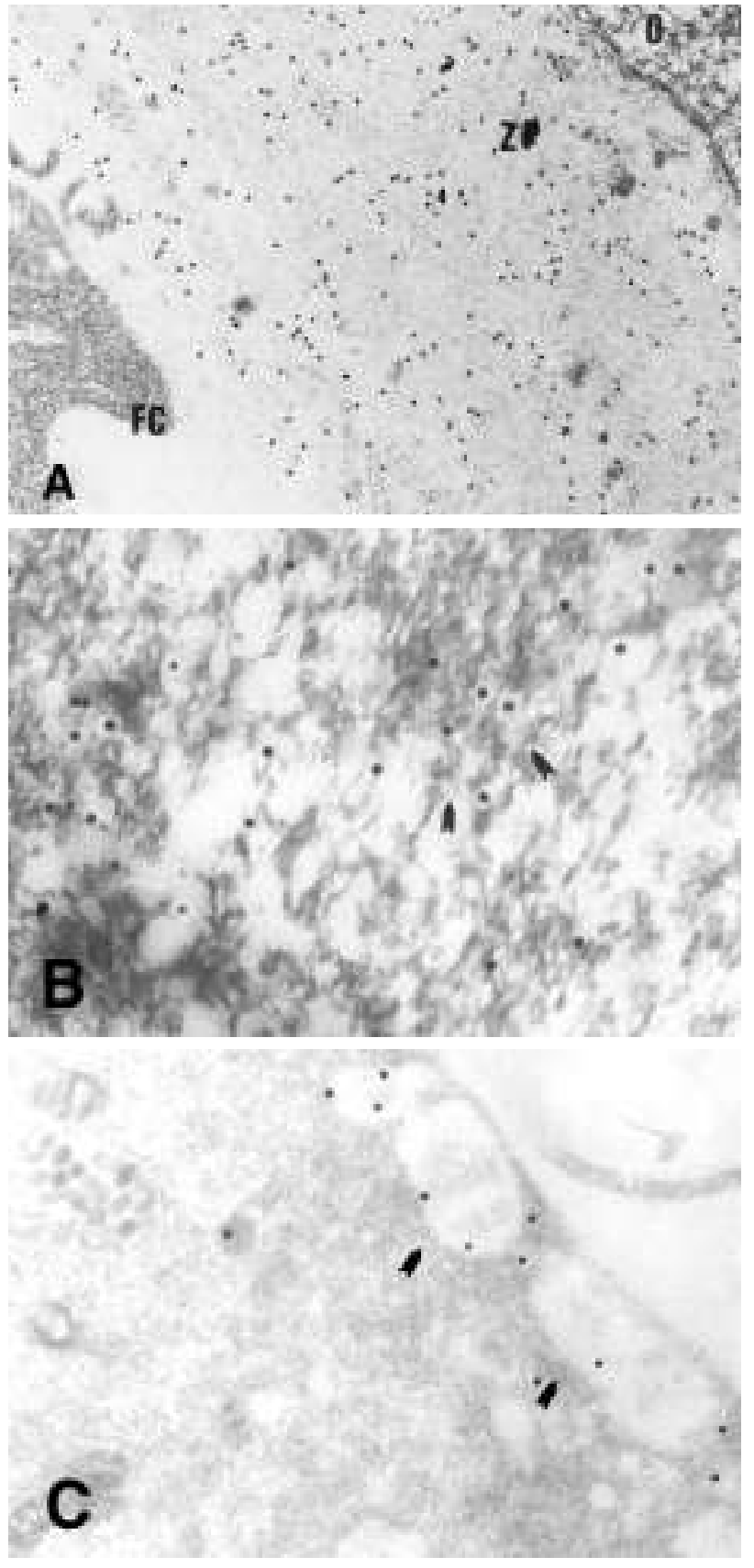

Figure 1.A,B,C. WGA staining. (a). Numerous binding sites are uniformly distributed in the ZP. (b). The gold particles are also located in the vesicles present in the ooplasm and (c) in a follicular cell (arrows). a x 32000; b,c x 42000. 0, ooplasm; FC, follicular cell.

tially located to the inner region of the ZP (Figure 3 ). Oocytes incubated with RCA-I showed a differential labelling throughout the ZP. A high concentration of gold particles was preferentially associated with the inner layer of the ZP, whereas they progressively decreased towards the portion in contact with the follicular cells (outer ZP) (Figure 4).

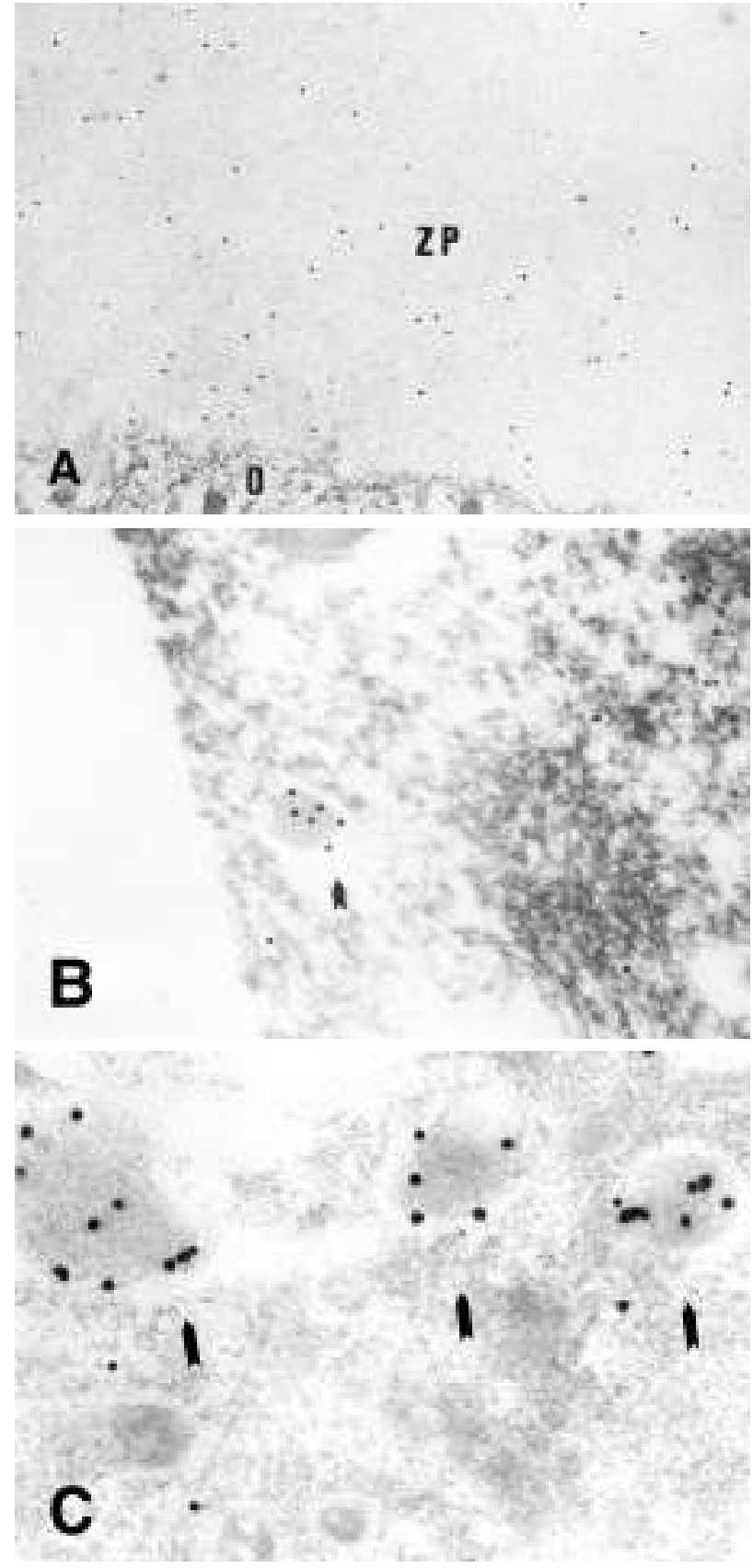

Figure 2.A,B,C. Con-A staining. (a). Binding sites are moderately and sparsely distributed in the $Z P$. (b). The vesicles (arrows) present in the ooplasm and (c) in the follicular cell are also labelled. a x 26000; b x 42000 (gold particles 10nm); c x 42000. 0, ooplasm; FC, follicular cell.

Sialidase digestion prior to RCA-I staining promoted new binding sites over the outer portion of the ZP (Figure 5a).

SBA, after enzymatic degradation, preferentially labelled two bands of the ZP: the inner and intermediate bands. The outer part of the ZP showed scarce binding sites (Figure 6). 


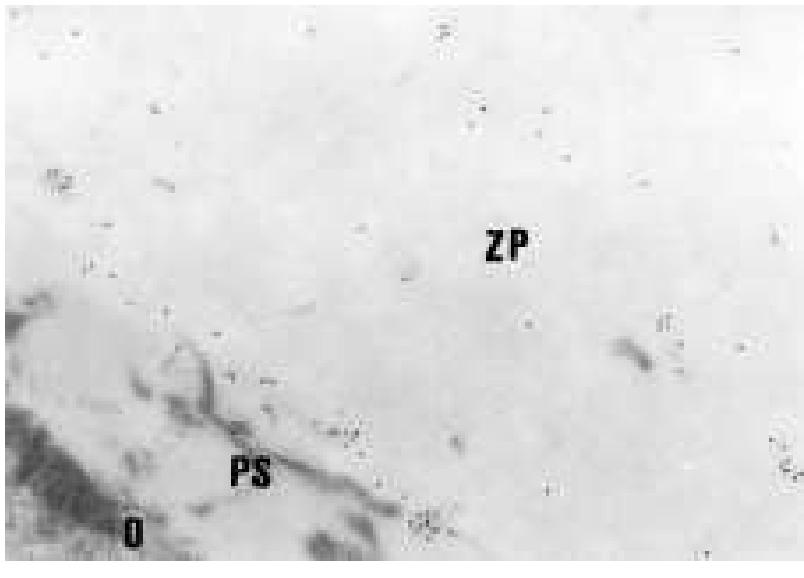

Figure 3. UEA-I staining. (a). A few reactive sites are localised mainly in the inner ZP. $x$ 26000. 0, ooplasm; PS, perivitelline space.

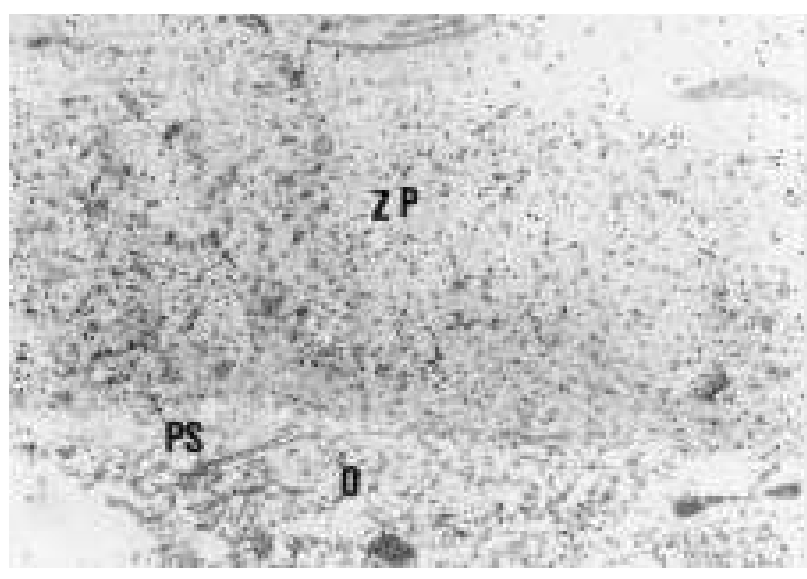

Figure 4. RCA-I staining. The labelling is higher in the inner layer of the ZP and it progressively decrease towards the outer portion of the ZP. x 19000. 0, ooplasm; PS, perivitelline space.

PNA reactive sites were slightly and sparsely distributed in the ZP only after the cleavage of sialic acid residues. No labelling was observed with DBA and LTA.

\section{Ooplasm}

A population of vesicles reactive to WGA (Figure 1b), Con-A (Figure 2b) UEA-I, sialidase/RCA-I (Figure 5b), sialidase/PNA and sialidase/SBA was evidenced in the ooplasm. Other cellular organelles, such as mitochondria and endoplasmic reticulum, were devoid of any labelling.

\section{Granulosa cells}

The cytoplasm of the granulosa cells contained numerous vesicles that displayed reactivity with

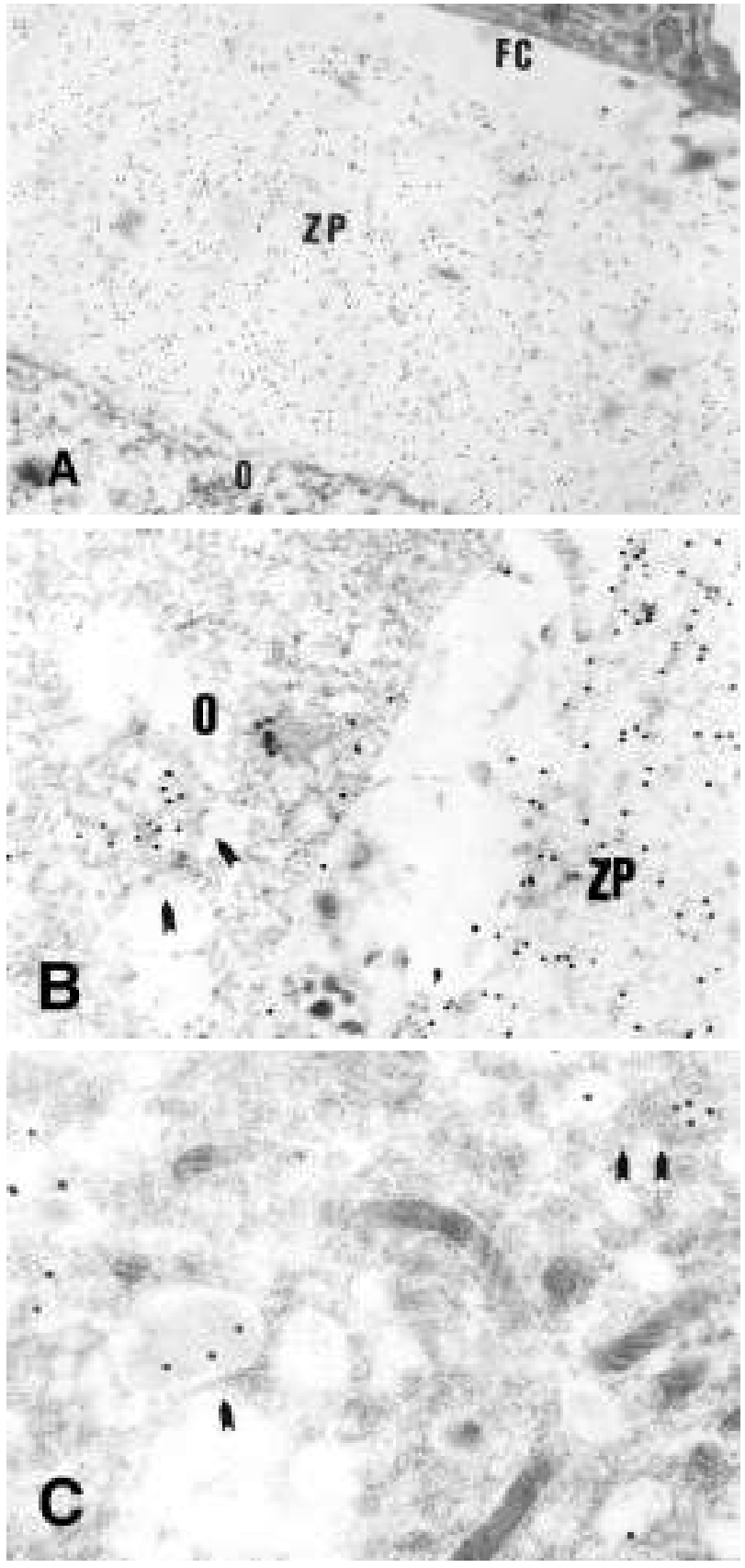

Figure 5A,B,C. Sialidase/RCA-I staining. (A) Sialidase degradation prior to RCA-I staining promotes new binding sites over the outer ZP. Reactive sites are also localised in vesicles (arrows) present in the (B) ooplasm and (C) in follicular cell. A x17000; B x27000; C x40000. 0, ooplasm; FC, follicular cell.

WGA (Figure 1C), Con-A (Figure 2C), UEA-I, sialidase/RCA-I (Figure 5C), sialidase/PNA and sialidase/SBA.

\section{Controls}

Control sections did not show any appreciable reactivity, confirming the specificity of lectin labelling. 


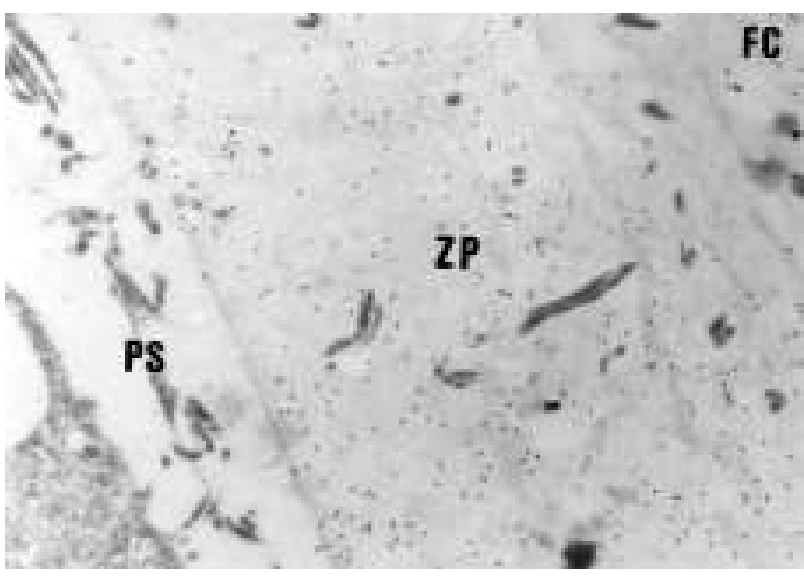

Figure 6. Sialidase/SBA staining. (a). SBA bound preferentially the inner and intermediate bands of the ZP after the cleavage of sialic acid residues. (b). $x 17000$. 0 , ooplasm; PS, perivitelline space; FC, follicular cell.

\section{Discussion}

The porcine ZP is composed of three structurally and immunologically distinct glycoproteins denominated PZP1, PZP3 $\alpha$ and PZP3 $\beta$ (Dunbar et al., 1980; Hedrick and Wardrip, 1986; Yurewicz et al., 1991). PZP $3 \alpha$ and PZP $3 \beta$ are highly glycosylated and possess both $\mathrm{N}$ - and $\mathrm{O}$-linked oligosaccharide chains (Yonezawa et al., 1997; Yurewicz et al., 1992). It has been suggested that carbohydrate chains of a mixture of PZP $3 \alpha /$ PZP $3 \beta$ have marked functional relevance in sperm binding.

In the present study, the ultrastructural identification of the porcine ZP glycoproteins, allowed us to obtain a detailed in situ localization of the oligosaccharide chains. The reactivity of the ZP to WGA and Con-A indicates the occurrence of GICNAC and $\alpha$-mannose residues, respectively. These carbohydrates are uniformly distributed throughout the entire thickness of the ZP but GICNAc residues are more abundant than $\alpha$-mannose ones. UEA-I reactivity suggests the presence of $\alpha$-fucose residues which are preferentially located in the inner region of the ZP. In our previous histochemical study carried out in the porcine $Z P$ with a light microscope, Con-A and UEA-I-binding sites were not identified (Parillo et al., 1996). This disagreement between the results obtained at light and electron microscopy could probably be explained by the scarce amounts of $\alpha$-mannose and $\alpha$-fucose residues. Fucose was identified by UEA-I, but not by LTA, which has a similar nominal specificity for $\alpha$-fucose as UEA-I does. This apparent discrepancy in lectin behaviour could be due to the different types of linkages that binds fucose to penultimate sugars. In particular, fucose visualized by LTA seems to be involved in the linkages with GICNAC and/or D-Gal, while fucose recognized by UEA-I seems to be bound to D-Gal (Menghi et al., 1989).

The positivity of SBA and PNA lectins only after sialidase digestion indicates the presence of sialic acid-GalNAc and sialic acid- $\beta-G a l-(1-3)$ GalNAc as terminal sequences in sialoglycoproteins. These sugar sequences were differently distributed throughout the zona matrix. In fact, the disaccharide sialic acid-GalNAc was present, above all, in the inner and intermediate bands of the ZP whereas the trisaccharide, sialic acid- $\beta$-Gal-(1-3) GalNAc, was sparsely distributed through the ZP.

RCA-I reactivity indicates the presence of the terminal disaccharide, $\beta$ Gal-1-4GICNAc, which was located more densely in the area closest to the oocyte plasma membrane. This dimer was also found penultimate to sialic acid and distributed in the outer and intermediate portions of the ZP.

Our findings are in agreement with previous investigations carried out on several mammalian ZPs. In fact, using lectin histochemistry at light and electron microscopy, it has been demonstrated that, in the $Z P$, an inner and outer layer can be identified, suggesting that the carbohydrate moieties of the ZP are asymetrically distributed (Avilés et al., 1994, 2001; Parillo et al., 1996, 1998, 1999, 2001a,b; Verini Supplizi et al., 1996; Roux and Kan, 1991; El Mestrah and Kan, 2001).

Indeed, the ultrastructural localization allowed us to identify three distinct zones containing different lectin receptors in the porcine ZP: the area localised close to the oocyte (inner ZP), an intermediate region and a portion contacting the granulosa cells (outer ZP). Glycoproteins containing terminal $\beta \mathrm{Gal}$ $1-4 G$ IcNAc and $\alpha$-fucose are confined prevalently in the inner ZP, those with terminal sialic acid-GalNAc are located mainly in the intermediate band while sialoglycoproteins with terminal sialic acid- $\beta$ Gal are more abundant in the outer layer.

Sialic acid, detected histochemically (Parillo et al, 1996) and biochemically (Dunbar et al., 1980) in the ZP of the pig, contributes to the high heterogeneity of the carbohydrate portion of the ZP matrix. It has been suggested that this terminal sugar keeps its associated glycoproteins impotent until the sperm-egg interaction has taken place.

Specialized vesicular aggregates, showing a lectin 
binding pattern superimposable to that of the ZP, were observed in the ooplasm as described in some laboratory rodents, suggesting their involvement as intermediary vehicles in the final processing and secretion of glycosylated ZP proteins (Avilés et al., 1994, 2000; El Mestrah and Kan, 2001). In addition, the detection of numerous vesicles in the cytoplasm of granulosa cells, with a pattern of lectin labelling resembling that of the $Z P$, suggests that also these cells could be involved in the active synthesis and secretion of the ZP glycoproteic material.

In conclusion, the present investigation provides an accurate account of the strategic localisation of lectin receptors throughout the porcine $Z P$, indicating that glycoproteins with 0 -linked oligosaccharides prevail in the inner and intermediate portions of the $\mathrm{ZP}$, whereas glycoproteins with $\mathrm{N}$-linked oligosaccharides are mainly localised in the outer ZP. In addition, this work enabled us to discover some glucidic residues, such as mannose and fucose, that were not revealed at the light microscope.

\section{Acknowledgments}

The authors wish to express their gratitude to Prof. G. Menghi (University of Camerino, Italy) for her helpful suggestions and criticism. The excellent technical assistance of Ms. M.G. Mancini is also gratefully acknowledged.

\section{References}

Avilés M, Martinez-Menarguez JA, Castells MT, Madrid JF, Ballesta J. Cytochemical characterization of oligosaccharide side chains of the glycoproteins of rat zona pellucida: an ultrastructural study. Anat Rec 1994; 239:137-49.

Avilés M, Jaber L, Castells MT, Kan FKW, Ballesta J. Modifications of the lectin binding pattern in the rat zona pellucida after in vivo fertilization. Mol Reprod Dev 1996; 44:370-81.

Avilés M, El Mestrah M, Jaber L, Castells MT, Ballesta J, Kan FKW. Cytochemical demonstration of modifications of carbohydrates in the mouse zona pellucida during folliculogenesis. Histochem Cell Biol 2000; 113:207-19.

Bleil JD, Wassarman PM. Structure and function of the zona pellucida: Identification and charcterization of the proteins of the mouse oocyte's zona pellucida. Dev Biol 1980; 76:185-202.

Bleil JD, Wassarman PM. Identification of a ZP3-binding protein on acrosome-intact mouse sperm by photoaffinity crosslinking. Proc Natl Acad Sci USA 1990; 87:5563-7.

Chapman JA, Wiebkin OW, Breed WG. Interspecific variation of zona pellucida glycoconjugates in several species of marsupial. J Reprod Fert 2000; 119:111-20.

Dunbar BS, Wardrip NJ, Hedrick JL. Isolation, physicochemical properties, and macromolecular composition of zona pellucida from porcine oocytes. Biochemistry 1980; 19:356-65.

El Mestrah M, Kan FKW. Distribution of lectin-binding glycosidic residues in the hamster follicular oocytes and their modifications in the zona pellucida after ovulation. Mol Reprod Dev 2001; 60:51734.

Epifano 0, Liang LF, Familiari MC, Moos Jr MC, Dean, J. Coordinate expression of the three zona pellucida genes during mouse oogene- sis. Development 1995; 121:1947-56.

Fléchon JE, Pavlok A, Kopecny V. Dynamics of the zona pellucida formation by mouse oocyte: An autoradiographic study. Biol Cell 1984; 51:403-6.

Hedrick JL, Wardrip NJ. Isolation of the zona pellucida and purification of its glycoprotein families from pig oocytes. Dev Biol 1986; 121:478-88.

Kan F, Roux WKE, St-Jacques S, Bleau G. Demonstration by lectingold cytochemistry of transfer of glycoconjugates of oviductal origin to the zona pellucida of oocytes after ovulation. Anat Rec 1989; 226:37-47.

Menghi G, Accili D, Bondi AM, Gabrielli MG. Enzymatic degradation and quantitative lectin labelling for characterizing glycoconjugates which act as lectin acceptors in cat submandibular gland. Histochemistry 1989; 90:331-8.

Menghi G, Bondi AM, Marchetti L, Gabrielli MG, Materazzi G. Glycohistochemistry of the mouse parotid gland. Investigation by lectingold techniques on Bioacryl and Lowicryl K4M embedded specimens. Eur J Histochem 1996a; 40:219-234.

Menghi G, Marchetti L, Bondi AM, Materazzi G. Sialylation patterns of the mouse parotid secretory granules. Combined deacetylation, enzymatic degradation and lectin-gold binding. Eur $\mathrm{J}$ Morphol 1996b; 34:181-5.

Parillo F, Stradaioli G, Dall'Aglio C, Verini Supplizi A. Characterization of the complex carbohydrates in the zona pellucida of mammalian oocytes using lectin histochemistry. Vet Res Comm 1996; 20:22536.

Parillo F, Stradaioli G, Verini Supplizi A. Glycoconjugates in small antral ovarian follicles of the River buffalo (Bubalus bubalis L.). Acta Histochem 1998; 100:1-15.

Parillo F, Verini Supplizi A. Glycohistochemical investigation of canine and feline zonae pellucidae of mammalian of preantral and antral oocytes. Acta Histochem 1999; 101:1-20.

Parillo F, Fagioli 0, Dall'Aglio C, Verini Supplizi A. Lectin histochemical detection of sulfoglycans in the zona pellucida of mammalian antral oocytes. Acta Histochem 2000; 102:1-10.

Parillo F, Verini Supplizi, A. Glycohistochemistry of the zona pellucida of developing oocytes in the rabbit and hare. Res Vet Sci 2001a; 70: 257-26.

Parillo F, Diverio S, Todini L, Fagioli 0. Histochemical detection of the lectin-binding carbohydrates in the zona pellucida during oocyte growth in the wild boar (Sus scrofa scrofa). Vet Res 2001b; 32:58190.

Roux WK, Kan F. Changes of glycoconjugates contents of the zona pellucida during oocyte growth and development in the golden hamster: a quantitative cytochemical study. Anat Rec 1991; 230:347-60.

Scala C, Cenacchi G, Ferrari C, Pasquinelli G, Preda P, Manara, GC. A new acrylic resin formulation: a useful tool for histological, ultrastructural, and immunocytochemical investigations. J Histochem Cytochem 1992; 40:1799-804.

Sinowatz F, Amselgruber W, Topfer-Petersen E, Totzauer I, Calvette J, Plendl J. Immunocytochemical characterization of porcine zona pellucida during follicular development. Anat Embryol 1995; 191:416.

Sinowatz F, Kolle S, Topfer-Petersen E. Biosynthesis and expression of zona pellucida glycoproteins in mammals. Cells Tissue Organs 2001; 168:24-35.

Verini Supplizi A, Monaci M, Stradaioli G, Greve T, Parillo F. Identification of glycoconjugates in the zona pellucida of in vitro matured and tubal unfertilized bovine oocytes by lectin histochemistry. Anim Reprod Sci 1996; 43:99-111.

Wassarman PM. Gamete interactions during mammalian fertilization. Theriogenology 1994; 41:31-44.

Yonezawa N, Mitsui S, Kudo K, Nakano M. Identification of an N-glycosylated region of pig zona pellucida glycoprotein ZPB that is involved in sperm binding. Eur J Biochem 1997;248:86-92.

Yurewicz EC, Pack BA, Sacco AG. Isolation, composition and biological activity of sugar chains of porcine oocyte zona pellucida $55 \mathrm{~K}$ glycoprotein. Mol Reprod Dev 1991; 30:126-34.

Yurewicz EC, Pack BA, Sacco AG. Porcine oocyte zona pellucida M( $r$ ) 55,000 glycoproteins: identification of 0 -glycosylated domains. Mol Reprod Dev 1992; 33:182-8. 